\title{
Using Cultural Framings to Disentangle Viliui Sakha Perceptions, Beliefs, and Historical Trauma in the Face of Climate Change
}

\author{
SUSAN CRATE
}

\begin{abstract}
This article explores how a community's perceptions of a changing climate may shift over time, and the ways in which certain cultural predilections emerge in the process. Through replicating the same focus group method with Viliui Sakha in 2008 and again in 2018 , the analysis reveals both continuity in cited changes as well as new emergent ones. Following this comparative exercise, the article further probes two culturally specific phenomena: how some inhabitants continue to attribute change to a long-disproven driver, de facto perpetuating a cultural myth, and how others expressed starkly contrasting perceptions of change. For both, the analysis reveals the importance of using a cultural framing founded in a people's vernacular knowledge system with a focus on historical precedence for the former case, and on sacred beliefs for the latter.
\end{abstract}

Keywords: climate change, cultural framing, longitudinal ethnography, vernacular knowledge, Viliui Sakha

$S^{i}$ ince the early 2000s anthropologists have begun investigating the cultural implications of anthropogenic climate change by tracking and analyzing local communities' observations, perceptions, understandings, and responses (Barnes and Dove 2015; Crate and Nuttall 2016, 2009; Dove 2013; Marino 2015; Strauss and Orlove 2003). This work has focused on "ways of knowing," or how a culture uses their Indigenous knowledge and/or local knowledge to understand the effects of climate change (Huntington 2000; Maldonado et al. 2016). This, in turn, has increased anthropology's capacity to make a difference in global change research (Crate, 2011a; Crate et al. 2017; Hiwasaki et al. 2014; 
Hou et al. Mekonnen et al. 2017). It has also fortified multi-stakeholder negotiations and evolving policy initiatives (Beck et al. 2014; Diaz et al. 2015; IPCC 2019; Tengo et al. 2014; Thaman et al. 2013; Yeh 2016).

In just the last five years the pace of changes due to global climate change are proceeding faster than models have predicted, largely due to the cascading effects inherent in the earth system (IPCC 2021). The Arctic is seeing the most rapid change and, within it, the Sakha Republic, home to one of the most extreme climates in the Arctic, is quickly transforming. This has prompted significant research within the Republic. There has been a surge of social science studies on climate change, especially in northern Sakha areas. Among the many examples, one study documents how the combination of ice thaw and rock erosion affects settlements, "The village is gradually losing its coastal lands. People are forced to move their houses and outbuildings due to the constant breakage of the shore" (Ignatieva 2014: 88-89). In Oymyakon, inhabitants report how their hay fields are substantially wetter and in a constant supersaturated state, making haying for their herds impossible (Solovyeva 2021). In another study, a team surveyed householders living with extreme conditions of climatic variability and permafrost degradation. Of them, 85 percent reported that their homes had subsided substantially in recent years (Svinoboev and Neustroeva 2017). A final example is a study focused specifically on how changes in the permafrost are perceived by inhabitants of the Sakha Republic's Central regions (Vinokurova et al. 2019). Using an Indigenous research paradigm, the team interviewed rural inhabitants and discerned both their concern and also their eagerness to assist nature to heal her wounds.

I contribute to this activity by exploring how researchers can gauge the reorientation, over time, in inhabitants' perceptions of a changing climate. In other words, analyzing how a specific culture observes, perceives, understands, and responds to the local effects of climate change and also how, over time, their cultural orientations change. I begin by comparing my results from two studies, ten years apart, using identical methods to show how inhabitants perceive change over time. This shows that changes cited earlier not only continue but are described in more qualitative detail as the changes have developed and intensified. In addition, inhabitants cite new changes. Within this comparative exercise, I probe further two culturally-specific phenomena brought to light through my analysis. The first is how inhabitants continue to attribute change to a long-disproven driver, de facto perpetuating a cultural myth. The second is how inhabitants expressed starkly contrasting 
perceptions of change, specifically from 'changes are unprecedented and dramatic,' to 'nothing has changed, all is as it was before.' For both I argue the importance of using a cultural framing founded in a people's vernacular knowledge system with a focus on historical precedence for the former and on sacred belief for the latter.

\section{The Longitudinal Context}

I have conducted research with Viliui Sakha communities, in the western Sakha Republic, Siberia, since 1991. Viliui Sakha are one of two major enclaves of Sakha. Their name reflects the fact that they live along the Viliui River, a major tributary of the Lena River. The ancestors of both Viliui Sakha and Sakha of the Central regions settled in these two areas because of the abundance of lush natural hayfields, characteristic of the alaas that dot the landscape. Alaas are a cryogenic ecosystem underlain with ice-filled permafrost that are unique to the Sakha Republic. They are the original ecosystems that Sakha's Turkic ancestors inhabited when first arriving from the south, adapting their horse and cattle agropastoralism to the extreme northern climate (Gogolev 1993). Alaas are made up of a circular lake, bordered by hayfields that transition to taiga or boreal forest. Prior to the Soviet period, Sakha lived 'by the alaas' in agha uuha (patrilineal clan). The hayfields provided all necessary pasture and fodder for their herds and the alaas flora and fauna all their needed supplementary forage. These former homestead areas are called ötökh. Most Sakha know their ancestral lineage and the location of their ancestral birth alaas. Many of them continue to practice an annual pilgrimage there to feed the ancestors (Crate 2021; 2022). Over my thirty years of research, I have mostly worked with the communities of Elgeeii and Kutana (Figure 1). Many rural Sakha continue meat and milk production, supplemented by foraging. However, historical shifts, especially the collectivization of the Soviet period and the increase in consumer culture in the post-Soviet period, have greatly lessened these practices.

I set the stage for the discussion herein by providing the context of my work on climate change, which began in 2005. At the time I was conducting a preliminary analysis of surveys for a project on future sustainability. One finding stood out. In response to the final question, "Is there anything else you would like to tell me that I have not asked you about?," 90 percent of respondents mentioned something having to do with their climate: how the winters were not so cold and the sum- 


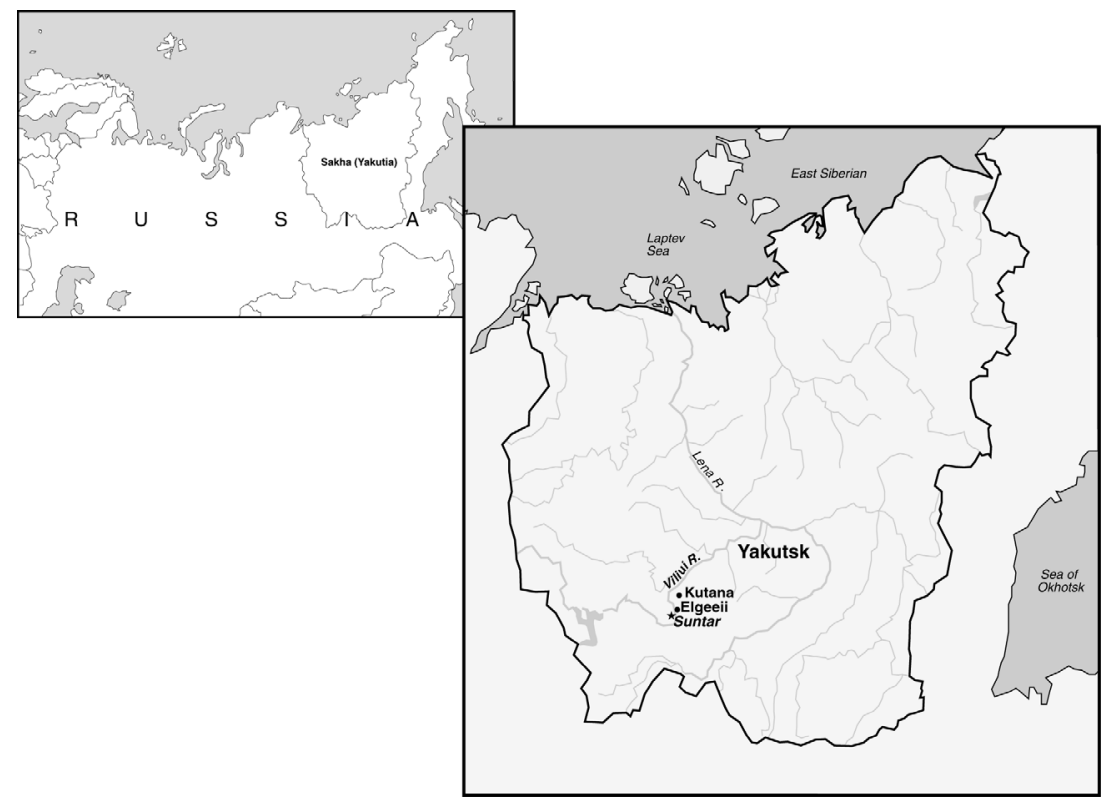

Figure 1. The contemporary Sakha Republic, above showing its location within the Russian Federation and to the right showing the location of the capital city, Yakutsk, the Vilui River, the Suntar regional center and the two research villages, Elgeeii and Kutana.

mers not as hot; how seasonal timings were off; how it rained at the wrong times; how new birds and animals had arrived. I knew from my background in environmental sciences and my specific understandings of climate change issues in Arctic ecosystems that many of the concerns they raised were due to climate change. I also knew from my prior work with these communities that they practiced many adaptations, enabling them to be successful horse and cattle breeders in the extreme continental climate of northeastern Siberia (Crate 2006a).

To better understand these local observations, I conducted oneon-one interviews with thirty-three elders from my two main research villages in the final three weeks. Of the thirty-three, ten mentioned how Jyl Oghuha (the Bull of Winter) was no longer arriving. Sakha depict the three-month, windless, snowless, dry, winter period as the time of $J y l$ Oghuha. Accordingly, the bull arrives in late November-early December, once the cold, dry conditions have set in. Jyl Oghuha holds those conditions in place until, in late February, a slight warming begins and one of his horns falls off. A week or so later the second horn falls off. Finally, in another week or two, the bull's head falls off and snow 
begins to fall, signaling spring. In the new climate regime, that deep cold is no longer arriving on time or staying as long. In short, Jyl Oghuha is not arriving. In that moment it struck me: We know a lot about how climate change is affecting the physical systems of the planet, but we do not know much about how it is affecting the cultural systems (Crate 2008). Before leaving the field that summer, I secured the communities' support to collaborate on a new project focusing on the changes they had shared. I planned to work with assistants in each village to organize research activity.

We began this formal research in the summer of 2008, facilitating focus groups and semi-structured interviews in four villages-in Elgeeii and Kutana, where I had worked since 1992, and in Khoro and Toloon, where I started research in 1999. Together the four villages represented a trajectory of population sizes from 200 to 3,000, giving insight into how the smaller and thereby more subsistence-based populations compared with the larger and more employment-oriented ones across all questions of change. In the focus groups we first asked participants to fill out a four-column chart, listing first each of the changes they had seen, then what they thought was causing each of them, next how each was affecting them and their family or community, and finally, how they thought it would be if each change continued for ten years. We followed the focus groups with semi-structured interviews, which allowed us to delve more deeply into specific inquiries. These methods highlighted inhabitants' detailed and specialized understandings of how global climate change was affecting their local ecosystem and culture.

Analysis of the focus group and interview data rendered nine changes that a majority had shared: winters are warm, summers are cold, too much water on the land, too much rain, too much snow, seasons coming at the wrong times, sudden temperature changes, new species of animals, and more floods. It also revealed four main explanatory stories. The most popular was Viliui gidroelektrostantsiia (GES; hydroelectric station), referring to the effect of the expansive reservoir of the hydroelectric station constructed in the late 1960s to provide electricity for processing newly discovered diamonds. The second most popular explanation for the changes inhabitants were observing was due to the wet year/dry year cycle that characterizes their ecosystem. The third most popular explanation was too much tekhnika (technology, referring to cars, trucks, tractors, etc.). This was largely voiced by older inhabitants, most of whom have seen the world move from a place where all work is done by humans or animals to a highly mechanized system. 
Lastly, the least reported explanation and one mostly put forward by village teachers and well-read elders, was climate change (Crate 2011b).

In 2008, the most critical change for inhabitants was that of "too much water on the land" (Crate 2011b). Sakha's environment is characterized by a specific rhythm of wet and dry cycles. The wet period is a time when it is important to manage the water for hay production. The combination of the wet cycle and climate change effects, namely increased precipitation and thawing permafrost, rendered far more water on the land than many inhabitants had seen in their lifetimes. Not only did it make resource access and travel problematic, it also evoked fear. In one of our follow-up questions we asked if people had seen this much water on the land before to understand if Sakha had any adaptations to this amount of water on the land. The only reference they had was a flood in 1959 where people recalled canoeing to the post office. The main difference between then and now was that in 1959 the water only stayed for a few days whereas in 2008 it was staying from season to season.

We spent that winter further analyzing and developing a survey to administer the next summer to test our qualitative findings across the populations. The final section of the survey was about 'climate change,' here explicitly using the term for the first time in the research project (several participants used the term to attribute the changes as one of the explanatory stories, but we had not used the term in our elicitations either in the focus groups or interviews). The survey responses showed that all participants had heard of climate change, had known of it for the past five years (from 1998 to 2003), and had learned about it via newspaper, TV, or radio. However, the majority did not understand its connection to the local changes they reported.

In response, I invited permafrost scientist Alexander Fedorov, with whom I had collaborated since 2005, to conduct 'knowledge exchanges,' community gatherings to elicit Indigenous knowledge and local knowledge in the form of audience testimonies of change and also to show his research documenting the scientific knowledge using familiar landscapes and explanations (Crate and Fedorov 2013a). We conducted eight such exchanges in the summer of 2010. Based on the eight communities' encouragement to share this information as widely as possible, we spent the next three years cowriting a booklet with knowledge exchange participants in the Sakha language to share the information widely (Crate and Fedorov 2013b). We were able to distribute 3,000 copies to all village and regional center administrations, schools, and libraries throughout the Viliui regions. 


\section{Ten Years Later}

I returned to the villages after a five-year hiatus conducting research in Mongolia and Wales. I had a two-year fellowship to write a longitudinal ethnography spanning my work with Viliui Sakha (Crate 2021). After arriving in the field in the summer of 2018, I decided to replicate my 2008 field methodology to solicit community observations, perceptions, understandings, and responses to the local effects of climate change. This decision was prompted by two events at the start of 2018 fieldwork. First was my initial meeting with Alexander Fedorov at the Melnikov Permafrost Institute in Yakutsk. Since we began our collaboration, he had consistently greeted me with a welcoming smile and handshake after which we would share a few bits of personal and family news and then move on to our mutual work. In 2018, he wasted no time moving directly to his concerns about the pace of permafrost degradation. The signs of his distress were visceral; his mood was uncharacteristically solemn and his energy low. He showed me satellite images that illustrated the extent of permafrost degradation in the landscapes that Sakha depend on for hay, pasture, and other resources. He told of how he and several other researchers and policymakers were pushing legislation to protect the permafrost. Their main aim was to protect against the appropriation of land via two federal programs. First, was the domestic Far Eastern Hectare program, which offers one hectare of land in the Russian Far East to Russian citizens and of which many fear will result in encroachment onto Indigenous areas, and land grabbing by outsiders (Fondahl et al. 2019).

Second was the international program Territoriia operezhaiushchego razvitiia (Territory of Advanced Development), to attract foreign investment by relaxing restrictions for resource exploitation. The results of the latter program were evident in the taiga forests east of Lake Baikal after Chinese interests were able to purchase and subsequently deforest thousands of hectares there. Multiple news stories, like "China's Voracious Appetite for Timber Stokes Fury in Russia and Beyond" (Meyers 2019), and the abundance of YouTube videos to educate people on the issue (e.g., "Siberia" 2018), document residents' inability to prevent the deforestation. Alexander stated that if such buy-ups of land and deforestation happened in the Sakha Republic, it would completely devastate the permafrost. Alexander's distress unnerved me and also steeped my curiosity about whether and how the communities I had collaborated with for several decades had greater awareness of conditions or not. 
My encounters after first arriving in the villages was the second reason to replicate 2008 methods. When I met with the head of Kutana and he learned that I was collaborating with a permafrost scientist, he began describing how their many formerly flat ötökh in the outlying alaas had become roller coasters from the permafrost's thawing due to global climate change. Soon after, many inhabitants spoke of similar changes in their ancestral and birth alaas. This told me that the changes were more apparent but also that inhabitants had gained a greater understanding of the effects of climate change since 2008. I realized if we replicated the 2008 focus groups, we could perhaps bring the difference into greater relief.

It is in this context of both my main collaborator's change of mood and local inhabitants' newfound literacy of climate change that I decided to repeat the 2008 focus group methods. I hoped to shed some light on how community perceptions had reoriented and, more generally, how humans themselves realign their perspective over time, in relation to a changing world.

\section{Methods and Analysis}

In 2018, we facilitated focus groups and semi-structured interviews in four villages. I worked with a local assistant in each village who organized a group of six women for one focus group and a group of six men for the other, each with an even number of youth, middle aged, and elderly respondents. We began by asking each participant to complete a written table. In the first column they were asked to list changes they had observed, in the second what they thought the cause of each change was, in the third how each change was affecting them and their household, and in the last how they thought it would be in ten years if each change continued. Having a sheet from each participant allowed us to avoid any issues related to one or two people dominating the conversation since we could ask others to share about what they had written. We then created a group table on a blackboard and listed all participants' responses. Following, we tallied the most concerning issues and discussed them as a group. After facilitating the eight focus groups, we conducted semi-structured interviews with inhabitants not involved in the focus groups. This gave us a chance to ask about changes in a more detailed way.

We transcribed all written and recorded responses then used textual analysis to analyze into thematic groups. 
Table 1. Main changes articulated by 2018 focus group and interview participants with cross-reference to 2008

\begin{tabular}{|c|c|c|c|}
\hline Theme & $\begin{array}{l}\text { Year(s) } \\
\text { reported }\end{array}$ & $\begin{array}{l}\text { Number of } \\
\text { responses }\end{array}$ & Specific expressions \\
\hline $\begin{array}{l}\text { Plant, } \\
\text { animal, } \\
\text { and insect } \\
\text { changes }\end{array}$ & $\begin{array}{l}2008 \\
2018\end{array}$ & 62 & $\begin{array}{l}\text { Now the plants and trees don't green like } \\
\text { before, lots of new insects, fewer birds and } \\
\text { animals, different kinds of mosquitoes, less } \\
\text { ducks, lots of horse flies, fewer butterflies, } \\
\text { new birds have come, fewer fish, kÿöregei } \\
\text { (skylark) is gone, swallows are gone, fewer } \\
\text { n'urguhun (snowdrops), fewer hares, fewer } \\
\text { wood birds }\end{array}$ \\
\hline
\end{tabular}

\begin{tabular}{lll}
\hline $\begin{array}{l}\text { Temper- } \\
\text { ature }\end{array} 2008,52$ & $\begin{array}{l}\text { Winter is warm, summer is cold, summer is } \\
\text { very, very hot, lots of freezing, it freezes in } \\
\text { changes }\end{array}$ \\
$\begin{array}{l}\text { June, warming, the river ice goes early (in } \\
\text { spring), the river ice freezes late (in fall), tem- } \\
\text { peratures change very suddenly, the summer } \\
\text { wind is cold }\end{array}$ \\
\hline
\end{tabular}

Drought $2018 \quad 40 \quad$ The lakes are drying, drought years have
come, land is drying, the ground surface is cracking, the old homeplaces (ötökh) are now like roller coasters, little rain, no rain in spring, plants and trees have dried

\begin{tabular}{lll}
\hline $\begin{array}{l}\text { Seasonal 2008, } 39 \\
\text { change }\end{array} 2018$ & $\begin{array}{l}\text { Summer is late, seasons change earlier, } \\
\text { spring is early but lasts long, spring is cold, } \\
\text { fall is longer, seasons change very fast, sea- } \\
\text { sons come at wrong times, winter comes late, } \\
\text { winter does not come at wintertime }\end{array}$ \\
\hline
\end{tabular}

\begin{tabular}{|c|c|c|c|}
\hline $\begin{array}{l}\text { Strong } \\
\text { constant } \\
\text { winds }\end{array}$ & 2018 & 28 & $\begin{array}{l}\text { Numerous strong winds and blizzards, } \\
\text { before no wind and the cold stood vertically, } \\
\text { winds take away all water in spring }\end{array}$ \\
\hline $\begin{array}{l}\text { Floods/ } \\
\text { water on } \\
\text { the land }\end{array}$ & $\begin{array}{l}2008 \\
2018\end{array}$ & 19 & $\begin{array}{l}\text { Lots of spring flooding, water on the land, } \\
\text { lots of villages under water (other areas of } \\
\text { republic), when ice goes, fears of flood }\end{array}$ \\
\hline Pollution & 2018 & 17 & The river water is polluted, the air is polluted \\
\hline $\begin{array}{l}\text { Precipi- } \\
\text { tation } \\
\text { changes }\end{array}$ & $\begin{array}{l}2008 \\
2018\end{array}$ & 12 & $\begin{array}{l}\text { Lots of snow, fewer thunderstorms, rain falls } \\
\text { heavy and fast, snow is thin until the New } \\
\text { Year }\end{array}$ \\
\hline $\begin{array}{l}\text { Human } \\
\text { health }\end{array}$ & $\begin{array}{l}2008 \\
2018\end{array}$ & 10 & $\begin{array}{l}\text { Increase of strokes and heart attacks, lots of } \\
\text { cancer }\end{array}$ \\
\hline Forest fires & 2018 & 7 & Lots of fires \\
\hline Village life & 2018 & 6 & $\begin{array}{l}\text { People's characters have changed, youth are } \\
\text { developing differently, people are moving } \\
\text { to the city, there are fewer cows, newborn } \\
\text { horses and cattle are sickly }\end{array}$ \\
\hline
\end{tabular}




\section{The Main Changes in 2018}

There was both a continuation of changes reported in 2008 and new ones. Table 1 is a consolidation of responses into general thematic groups with the variety of verbatim changes that participants described. Those changes that continued were described in greater detail; for example, the change in winter temperatures. The 2018 participants explained the character and quality of warmer winters, explaining how there used to be a month or more of $-50^{\circ}$ Celsius temperatures whereas now they are lucky to get two days of those low temperatures. Several elders provided a window into the difference in temperatures using a sensory mode, of how they knew it was not getting as cold because they no longer heard the "sound of cold."

It was cold before. It would reach -60 or -70 degrees [Celsius]. When you would exhale into the air, just breath out of your mouth, it looked like smoke and as it fell it made a sound "Schuuuurrrr." Now it is not like that. (Kutana elder respondent, June 26, 2018.)

When it was cold enough to make a sound, we knew it was the "right" cold. We had no thermometers back then. The sound of cold was how we knew it was cold! (Kutana elder respondent, June 25, 2018.)

In 2018 participants also added depth and detail about summer temperatures. Whereas in 2008 most described summer as cold, in 2018, several interviewees described how the intensity of both hot and cold in summer had changed.

When the sun shines, it is very, very hot. But then, when a cloud comes and covers it, it turns very, very cold. I don't remember it being like that before. And also, now the sun is burning your skin. It never did that before. Yes, summers were hot before but the heat back then did not burn like it does now. Now when it is above 30 degrees [Celsius], it burns you. (Kutana middle aged respondent, July 2, 2018.)

On this topic, half of all respondents made some reference to how cold the summer nights were compared to before.

Another new change is that now the summer nights are very cold. Summer nights used to be warm. We played outside in the evenings and no one wore sweaters like we do now. It used to be so hot some nights that you could not sleep in the house! Now we sleep inside with blankets. They say the cold summer nights are why the hay and our gardens do not grow like they used to. (Kutana middle aged respondent, July 2, 2018.) 
Another change that had continued were differences in seasonal timings. In 2008, participants described how seasons were lagging and affecting seasonal activities (cows to pasture in spring, hay cutting in summer, berrying and other foraging in late summer and early fall, etc.). Descriptions in 2018 focused on the quality of change in the seasons. Inhabitants described how spring would arrive early but last longer-as opposed to it arriving 'on time' and moving gradually into summer with a constant level of warming.

The big change now is how temperatures change very quickly, from one day to the next. It used to be warm, warm, warm and then it gradually changed and the fall would gradually get cool. (Kutana elder respondent, June 26, 2018.)

Inhabitants explained how the fall season, which formerly was an elongated and gradual change to winter, now suddenly changes to bitter cold early on. This is followed by several warming and freezing cycles before winter continues.

A third change that carried over the decade were changes in plant, animal, and insect populations. In 2008 participants explained how they were seeing new species and also noticed that some regular species were less and less. In 2018 inhabitants continued this discussion but with more depth and breadth to their descriptions. For example, hunters commented that the fur of certain animals no longer "ripens" sufficiently in the warming winter to be worth what they once were. Many elaborated more on how plants had changed. Much of this had to do with one of the nine main changes reported in 2008, too much water on the land, that had now affected the landscapes' vegetative cover. Additionally, whereas in 2018 inhabitants observed drought conditions, there nevertheless remained many areas that had transformed into water ecosystems, due to the persistent water on the land.

Within the broader category of changes in precipitation, comments such as "too much rain" and "too much snow" held constant, but also had other details not articulated in 2008. When people talked about "too much rain" in 2018, they detailed aspects of the quality of rain: how it came suddenly and would rain huge amounts in a very short period. Similarly, when people described snowfall, they provided new detail about how snow arrives very suddenly and late in the season as opposed to the former pattern of snowfall starting in September and continuing through to December when it got too cold and dry to snow.

Beyond the continuing changes from 2008, the 2018 focus groups and interviews revealed new changes, including drought, wind, pol- 
lution, health, fires, and the overall quality of village life. Participants' testimony shows an in-depth understanding of the drought.

The land has gone to drought and the surface is cracking. The trees and other plants dry and shrivel before it is time. Some of this is from the water on the land problem we had before and still have in some places but moreover it is because of the drought now. The wind takes up all the snow before it can melt in spring. (Toloon elder respondent, May 31, 2018.)

The timing of the drought was in sync with Sakha's vernacular understanding of wet and dry cycles in their ecosystem. Over centuries Sakha have observed and used this knowledge to manage their fields, cut hay, and to do other tasks on the land. The practice of creating a field system for hay so that water can be retained in times of drought and let free in times of floods can be traced back to Sakha's Turkic ancestors, the Kurykan in southern Siberia (Ermolaev 1991). The severity of the contemporary drought was compounded by the fact that starting in 2010 there were many efforts by the state to drain the water from the land by digging canals to the nearest waterway. Many inhabitants, and elders especially, complained of how the government contracted companies to drain the land who proceeded with no consideration of the natural contours or water patterns of the landscape.

The canal diggers do it wrong. Our ebe (grandmother, here referring to the water) should go to the south. It should go first to Oibon Lake. But they are sending it the wrong way, they are going uphill. Those who know the land are here but the canal diggers don't talk to them or even try to find them and ask. They are very stubborn and bring their map and show what they will do and tell us we know nothing. Because of them the land is already weak and will fall under your weight. They ruin our nature. That's right, they just take the money and run. They say "the good has bad and the bad has good." Yes, lots of water is bad but there are also lots of fish and we do not go hungry. If we don't have our water, we will go hungry. (Khoro elder respondent, May 27, 2018.)

Tightly tied to the issues of drought were the issues of wind. According to the nineteenth-century explorer Richard Karlovich Maak, wind is characteristic in the Viliui regions in spring and early summer but relatively nonexistent in late summer, fall, and winter ([1886] 1994: 505). Today inhabitants report that wind not only prevails in spring but is now constant year-round. For example, inhabitants mentioned how winter, once a very windless period, is now characterized by blizzards 
with high winds. The wind prevalence has also played a part in the drought. Several participants commented, "the wind takes all the water away in the spring; we have snowfall in winter, enough to replenish the land with water in the spring thaw but then the winds pick up in spring and the snow and water disappear with the wind!"

Another new change that many people discussed was the increase of forest fires, a change that clearly links to the intensified drought and constant winds. Some days in the summer of 2018 there were several dozen fires burning in the Sakha Republic at the same time. On days when the wind blew a certain direction, the village was in a cloud of smoke. Three years later we now know that the 2021 fires in Sakha are the worst in recorded history.

In 2018 there was more discussion of pollution, although environmental issues are not new in the Viliui regions (Crate 2002). Following the end of the Soviet period, inhabitants and policymakers alike gained knowledge about the environmental offenses of the diamond mining activities on the Viliui River. In the early post-Soviet period there were successful efforts to lessen the contamination. However, in 2018 there was evidence that new issues of river contamination threatened water quality and community health (Sakhalife 2018).

The final change that was not brought up in 2008 was the qualitative change in human interaction in the villages.

The next change I wrote about was the change in people's characters-now finding nice people in the village is very rare-they are hard to find. Before people used to converse and take time. You would meet someone on the street and stop and talk and know each other's news. Now everyone looks at their cell phone and they don't need you or anything. There is no interaction now, it is only over WhatsApp. (Toloon middle-aged respondent, May 31, 2018.)

I link this directly to the recent access that rural areas have had to highspeed internet. These kinds of observations also came to light in the context of interviews.

Before, people would visit each other a lot and have tea. This is where people learned the latest news and connected with each other. It was how we lived. Now it is already not accepted. When someone enters a house, the inhabitants ask "What did that person come in for?" and "What do they want?" Also, most households today don't even give tea but just ask, "What did you come here for?" Then, after that is decided, they shoo the person away. It is a huge change in our culture. Before when a person came in, you poured tea right away. I did this 
and saw my mother practice it also. She would go to see neighbors a lot. If she didn't go for a few days, she would get in a bad mood. She had to go and listen and chat. She always came back in a very good mood with all the news of the village. (Kutana middle aged respondent, June 13, 2018.)

I had also noticed these changes when I came to the field in 2018. After five years away, the difference in how people appeared and interacted in the village context was stark. Almost everyone I saw in the street, stores, and other public places were on their phone. Granted, I come from a culture with this same obsession. However, having spent several decades living and working in a Sakha cultural context where most of the exchange of information and sense of community was generated face-to-face and in meetings in the public places of the villages, this was a sudden contrast. Not only were people constantly texting each other, but the ubiquitousness of WhatsApp was undeniable. Seeing how important it was in people's lives, I asked to join the neighborhood WhatsApp group. However, after one day of my phone pinging almost every minute, I removed myself. The connection that this change in human interactions at the village level has to local observations, perceptions, and responses to climate change may not be apparent at first sight. However, as Anthony Nansen points out, face-to-face interactions are integral to human-environment understandings, "the ever more pervasive penetrations of people's lives by information and communications technology (ICT), and the consequences for human relations with the natural world, make it all the more precious and necessary to cultivate the particular qualities of embodied, oral conversation" (2021: 7).

The overall comparison of these two research periods, 2008 and 2018, shows that inhabitants are keen observers of changes over time based on their vernacular knowledge of place. They possess an intimate understanding of their immediate environment. Beyond that, what stands out for me are two important phenomena. The first is the tenacity of a cultural myth expressed as an explanatory story that has been debunked for years. The second concerns how inhabitants of the same place, even of the same age and gender, can relay contradictory responses about change in their immediate environment.

\section{The Tenacity of a Cultural Myth}

The most cited explanatory story that inhabitants used in 2008 and that many continued to use to explain why the changes were happening 
was due to the presence of the Viliui GES hydroelectric dam reservoir. Inhabitants described how water from the large surface area of the reservoir would evaporate into the sky, creating clouds that came over their areas to make the winters warm and the summers cold. At first I was stumped as to why it had such tenacious staying power, since in our earlier knowledge exchanges and the follow-up handbook, Alamai Tyyn (Crate and Fedorov 2013b), we had gone into a detailed explanation of the research that shows how the reservoir had only micro-climatic effects (Dyakonov 1975; Spesivtseva 1976). Considering that our research villages are a several hours' drive away from the reservoir, the water body has no significant effect. But there is more to this myth's tenacity than meets the eye.

From my early research on the discovery and exploitation of diamonds in the Viliui regions, I knew that since the onset of damming the Viliui River, it was a point of grave contention for most Sakha and one that brought up issues of ethnic inequality and environmental racism (Crate 2002). Among the many problems, some examples include 1) how Sakha settlements had only provisional diesel-generated electricity, until the government saw the diamonds; 2) how Russian and Ukrainian newcomers who came to work for the mines got much-improved living conditions compared to the villages, including central heat, hot and cold running water, and a several-times higher paycheck; 3) how the flooding of the reservoir area contaminated the Viliui River with phenols which, among other things, wiped out important fish like taimen and salmon; and 4) how the diamond mining process contaminated the Viliui River water with thallium and the region's ecosystem with radioactive fallout from to underground nuclear accidents (Crate 2002).

Among all the issues, one that remains perhaps most contentious to this day is the forced relocation of over 600 residents from the Chona Valley to make way for the floodwaters of the Viliui GES reservoir (Crate 2003). The Chona / Sadinskii area was rugged with mountainous regions and free-flowing rivers and streams. There were few pasturelands and the inhabitants mostly relied on reindeer herding, hunting, fishing, and foraging. The area was hard to access due to a lack of permanent roads. Because of this isolation and lack of agricultural areas, the Soviet government considered it without potential and consolidated three western naslegs (districts)—the Chonskii, Bragatsko-Sadinskii and Botobinskii-into one independent Sadinskii National Region, based on the common subsistence lifestyle of its reindeer herding inhabitants. In 1947 the government determined the Sadinskii National Region to lack any future perspective, and therefore made it part of the adjacent 
Suntaar region. Reasons included: 1) the hunting and reindeer-herding communities would never develop agriculture, considered their only hope for progress, 2) the overall population was too small and dispersed to ever become independent collectives, and 3) the population was too dispersed and distant from the Sadinskii regional center, making their administrative guidance difficult.

A little less than a decade later, with the discovery of diamonds in the Viliui regions, the Soviet government designated the entire Chona Valley to be flooded and to function as the Viliui hydro-electric station reservoir, which in turn would provide electricity for the exploitation and processing of the newly discovered diamonds. In the process, hundreds of thousands of acres of prime fields, woodlands and waterways containing hunting, fishing, foraging, haying and pasturing areas were slated to be submerged. The reservoir would also flood the Indigenous settlements along the Chona River. Inhabitants protested this change early on but were gradually silenced by governmental pressure, propaganda, and promises that their children would benefit from living adjacent to urban areas. In the early 1960s Chonians began to relocate. Between that time and 1967 when the waters consumed the Chona Valley, all 600 people relocated except for one elder who refused to leave and subsequently drowned in his home.

In 1997, when the Sakha Republic recognized the thirtieth anniversary of the Chona Valley flooding, surviving Chonians looked back at the move with remorse. One of them, at the time a doctor at the Novyi State Farm, explained,

Many moved from Chona, from Tuoi Khaia (literally "Clay Mountain") when they built the Viliui Sea (colloquial name for the reservoir). Today we look back at this as a great loss but at the time our parents really had no choice. They were simple people with fourth grade educations and when the Soviets told them the relocation was the best for them, they had to go along with it. I came to Novyi State farm as a girl, finished schooling and have worked as a doctor since. I see the medical results of this relocation. 270 people moved (to the Novyi State Farm from Chona) and from them, 207 have died, mostly from cancer and from the stress of the move and being torn from their (ancestral) land. The conditions here were bad then and remain bad to this day. (Mirny middle aged respondent, July 7, 1997.)

In the post-Soviet context many of the evacuated Chona residents still do not have adequate housing, initially promised them by the Soviet authorities. A small percentage of Chonians relocated to live with relatives 
or found work in established Viliui settlements. All former Chonians I interviewed spoke eloquently about the Chona Valley. "It was such a lush and wild place-moose and bear came up to our door-we lived off of hunting and reindeer-herding. Tuoi Khaia was the highest point for miles around and there, in spring, the first snowdrops bloomed. We would gather on the mountain's peak and dance ohuokhai (Sakha's circle dance)" (Mirny elder respondent, July 13, 1997).

In the summer of 2018, I spent a few days in Mirny, the original diamond center, and was reminded once again of the grief caused by losing those homelands. Most prominently, I found a book that documented over fifty personal reflections on the Chona homeland by elders who remember the forced relocation process (Grigorieva 2016). Several Sakha social scientists are currently creating a documentary entitled, Tuoi-Khaia: Stertaia iz Karty, no ne iz Pamiati (Tuoi-Khaia: Gone from Maps but not from Memories) with the goal of bringing attention to the tragedy of the flooding and displacement but also to the lack of any form of state assistance in the past sixty years (Vinokurova and Alekseeva 2021).

The emotionally-charged and unjust story of the dam serves as historical precedence that people continue to reference and which informs their anxieties about their future and who they can trust. It is not surprising that inhabitants blame the reservoir as the main cause of their observed changes now and into the future. The reservoir also represents something tangible to blame as opposed to climate change which remains an abstract concept. The timing of the establishment of the reservoir also plays into the myth's holding power. The first scientifically significant data for these regions showing the local effects of climate change occurred in the early seventies, the same time that the reservoir was fully established. This analysis clarifies the importance of understanding the historical backdrop of perception.

\section{Contemplating Contradictory Responses to Unprecedented Change}

I don't remember changes like this. The seasons used to come about very smoothly from one to the next and everything happened at the "right" times. Now we don't know when they will be. Spring arrives early but then never comes. And the winter is not as cold as before and instead of being still and snowless, we have blizzards all winter. (Elgeeii, middle aged respondent, June 7, 2018.) 
No, there are not many changes. I do not see them. I think maybe there are changes from year to year but nothing unusual. All is normal like before. (Elgeeii, middle aged respondent, June 7, 2018.)

These two quotes represent two opposite responses from the same focus group, from respondents of the same age and gender. In addition to such contradictory testimonies arising in focus groups, they also occurred during interviews. It was a stark contrast to go from one interview during which the respondent detailed changes in climate and weather and their effects on household food production and then to the next wherein the respondent said there was no change and that all was like it was before. The first time it happened, I considered it a fluke but then it recurred several more times that same research season. One explanation could be the human capacity to adapt to a new normal. Second, it could be a case of intergenerational forgetting. Thirdly, the fact that humans often deny a reality that is too overwhelming for them. Lastly, such contradiction can occur due to a cultural predilection, in this case, to the agency of words.

The human capacity to adapt can be considered both a blessing and a curse. As humans, we are highly adaptive, which means we do our best to find ways to adjust through changes and, if the changes continue, we also assume a new norm quickly. In this process, we quickly forget how things were. I have a personal experience of adapting to a new norm. One of my first thoughts after arriving in the villages in 2018 was that climate change was not really having an effect. I realized that I had gotten used to there being water on the land and the host of extreme conditions climate change had ushered in. I had adapted to this as a new normal. This was quite a wake-up call. Humans tend to adapt quickly to changes and life goes on in the villages, as it does around the globe, in the context of climate change. At the same time, due to the recent access to high-speed internet and the ubiquity of cell phones and WhatsApp, inhabitants are less and less connected to the immediate world around them. This results in less and less observations of change, a phenomenon directly linked to the next explanation.

Another way to explain the contradictory testimonies is as intergenerational forgetting. Elders say that winters are not cold anymore, when, in the same focus group, youth say that winters are too cold and they freeze. In interviews, when people talked about how warm the winters were, I would comment that they must think it is a good change. Most agreed, commenting that it required less wood for heating and allowed cows can go to the oibon (waterhole) instead of staying 
in the barns all the time. But after some thought, most changed their response; they stated that this change is not good because it is not how the ecosystem should be. Young people do not experience the seasons that their elders or even parents knew. Many talked about no longer wearing $u n t i$, the felt-bottomed reindeer hide boots that kept their feet warm and insulated them from the frigid earth, because the winters now are mild and too wet for the felt bottoms. Elders detailed how they used to have a full annual rotation of shoes, wearing different shoes for the turning of the seasons. Overall youth are growing up knowing a different climate, a different world, and a different climate world.

A third explanation for inhabitants' responses is how information is communicated to them. In 2008, there was a paucity of information on the local effects of climate change. By 2018 there were frequent articles filled with locally relevant information. However, instead of facilitating understanding, they instilled fear, now known to be a consequence of climate impacts (Cunsolo and Ellis 2018). These news stories represent a case of new knowledge in the wrong clothing. In short, recent news stories about how the permafrost is thawing is working counter to helping local people understand. In one of the articles, the author talks about how the permafrost is thawing and the land is falling, with no framing to explain it in a way that would be less dramatic and cultivate understanding for its readers (Gotovtsev 2018). Other 2018 articles also failed to come across as anything but catastrophic. As a result, our focus groups and interviews showed residents expressing panic, remarking "they [news stories] say the permafrost is melting and so we will go under water." The implications of this for residents is enough to instill fear and to trigger a state of denial. This is not a phenomenon unique to Sakha (Norgaard 2011). It exists in many of the efforts to communicate effectively about climate change, "Worrying data about the collapse of glaciers or the acidification of the oceans [or, in this case, the thawing of permafrost] leads to conclusions so huge and all-encompassing that the scale easily overwhelms our comprehension" (CBC 2021). Indeed, the issue of scaling, specifically scaling down the multiple global change issues to a human context is recognized as increasingly important to the project of turning around our current climate predicament (Haarstad 2014).

The final explanation is Sakha's understanding of the agency of words. One interviewee articulated it beautifully, as she reflected on "being Sakha," 
I am Sakha and I practice what Sakha do. You don't talk about yourself, saying, I am great or I am bad. It is all in the middle. You do your best, even when something goes well you don't talk about it. Also, if you have a bad disease you don't talk about it, because the disease will hear it and get worse. Sakha have that understanding. You also don't talk about your child as being this or that. You are careful and don't talk about it. If you can do a lot, you do a lot but don't talk about it. Also, you don't count, for example, I have this many this and this many that. You don't count your grandchildren or your great-grandchildren, because people will be jealous and you will make people feel badly. Most everyone does that. If you go somewhere far away, you don't talk about it. Only when you get back do you talk about it. It is the Sakha character. Sakha are naghyl (calm and not emotional on the outside). You may wonder why is that? We follow the sun. The sun here is that way. It takes a long time to rise and a long time to set. In other countries, the sun rises quickly, shines right away and then gets dark very quickly. People there need to go quickly so they can get everything done. (Kutana middle aged respondent, June 13, 2018)

She was relaying Sakha's understanding that words are ichchileekh (spirit-filled). In the frame of Sakha sacred belief, all of the living and nonliving world is sentient. The Soviet government repressed all outward expressions of Sakha belief. But witnessing this and other similar expressions of belief in contemporary life helped me to understand that Sakha's historical belief not only survived that period but also continues to provide a grounding for many to this day. Sakha's historical belief system is animistic and aligns with other ancient understandings of humans' relationship with the natural world (Gogolev 1994; Jochelson 1933; Maak [1886] 1994; Seroshevskii [1896] 1993). It posits Sakha as guests on a planet inhabited by sentient beings, both living and nonliving. Sakha's belief facilitates survival in their extreme climate through the enactment of annual rituals and daily practices. These practices placate the upper world gods and the earth ichchi (spirits), who, in turn, provide for them. Ichchi, inhabiting mountains, clouds, insects, trees, water, rocks, and the like, are able to think, be joyful, be offended, dream, and help someone (Nikolaev 1995: 98). Accordingly, words have ichchi (spirit), referred to as tyl ichchite (spirits of words): "Spoken words turn into a prophetic bird that flies according to the meaning of the words uttered and retells the original words" (Kulakovski 1979: 45). The very act of speaking words gives them the power to fulfill their meaning (Crate 2006b: 168; Ferguson 2019). Words are the conduit of power in, for example, the making of offerings, the solo improvised 
song, toiuk, and Sakha's circle dance ohuokhai. In this context, the Sakha language is critical to enacting all cultural practices, including the beckoning of the sentient beings, with which a Sakha person maintains all relationships. For example, water is a critical resource for Sakha and has a central place in their spirit world. A commonly held understanding is 'Uu ichchileekh, meaning "water has a spirit," and according to Sakha cosmology, humans need to pay respect to that spirit when they interact with it. "You can't see water as the river goes by but if a person speaks artistic words as the river runs by, it will braid itself in response" (Kulakovski 1979: 186). Again, it is the spirit of the words that are important here in enacting a change in the world.

Although tyl ichchileekh is a historical belief that was squelched by Soviet forces, there remain many signs that it has persisted into the modern day. Since my first work with Viliui Sakha in 1991, I have observed, on many occasions, how people do not to speak about certain things. They explain that by substantiating phenomena with words, you are inviting an opening to attack. For example, people do not speak highly about their children in order to protect them, despite how proud they may feel. In this case, it follows that talking about climate change also gives it the power to be real-and to invite escalating effects. In short, within the Sakha culture, words have an agency in and of themselves. But this is not unique to Sakha culture either.

\section{Other Cultures' Understandings of the Agency of Words}

Earlier anthropological and linguistic research show how other cultures attribute agency to words. I mention here just a few examples. Linguist Stanley Tambiah discussed the agency of words, "language is outside us and given to us as a part of our cultural and historical heritage; at the same time language is within us, it moves us and we generate it as active agents. Since words exist and are, in a sense, agents in themselves which establish connexions and relations between both man and man, and man and the world, and are capable of 'acting' upon them, they are one of the most realistic representations we have of the concept of force" (Tambiah 1968: 184).

Anthropologist Roy Rappaport alluded to the agency of words in his analysis of ritual behavior, with ritual "including within itself both word and substance," and "conceived as the informing of substance and the substantiation of form, a union of form and substance. Form-the 
ordering principle or agent-is often explicitly associated with word" (1974: 42-43).

Gary Witherspoon's article, "Language in Culture and Culture in Language," on Navajo language and linguistics, references the agency of words, also in the context of ritual: "Thought, the inner form, and speech, the outer form, are the means by which matter is organized, transformed, and controlled. All of the elaborate rituals of the Navajo are designed to aid the patient in ordering and controlling various aspects of his environment" (1980: 8-9). In some cultures, the practice of forecasting entails the power of words, specifically, in performance the speech act itself shapes how humans perceive change and the future they are entering with that change (Taddei 2013). One study looks at how words represent the central power reinforcing a corporation's false altruistic intent, to shield a company's true interest in exploiting a local community's resource base (Krauss 2018).

Field research can often bring to light how a specific culture considers talking or not talking about an issue. A colleague's comments on the topic communicate exactly how complex the process is to tease out how a culture assigns agency to words, "It's a valuable insight that in many cultures, speech is a form of action. Sherpa in Nepal don't like to talk about glacier lake outburst floods (GLOF) because it causes others to feel anxiety and to suffer; in fact, they think that it is good not to dwell on past disasters, recalling them" (Orlove 2018). Another colleague added additional insight, "the socio-religious concept of Nomdok (the concept that if you speak of the bad, bad will happen) is similar to making spiritual pollution, which can anger local deities, which then leads to disasters. When I was interviewing people in the Mount Everest region about the Dig Tsho GLOF (1985), the elders who lived through it hesitated to speak of it. When the potential Imja GLOF was spoken about, people brought up Nomdok in the same sentence and stopped from speaking further" (Sherpa 2018). Others have documented some form of this phenomenon. In casual conversations over the last ten years, I have heard colleagues mention how an Indigenous group had blamed the researchers who came to study climate change for causing it by the mere fact that they were talking to the local group about climate change and had brought instruments to measure various aspects of climate.

In many ways, Sakha's sacred belief that assigns such agency to words so that talking about change is dangerous and risky intertwines with other of the explanations above. In the context of intergenerational forgetting, the agency of words applies because if you do not explicitly talk about a phenomenon, it can be easily forgotten. Similarly, 
if you provide information that perhaps relays panic in a culture that prizes reticence and keeping emotions internal, it is difficult to avoid overwhelming inhabitants and triggering denial. It is even more challenging to communicate about phenomena as abstract and intangible as climate change. However, if a topic can't be breached due to these constraints, how can it be understood, adapted to, to the extent possible, and lived with into the future?

\section{Concluding Thoughts}

In this article I discuss my replication of methods investigating how affected communities perceive, understand, and respond to climate change. This brought to light how the local effects of climate change had intensified and increased in number, and also how people's perceptions of and responses had changed. In addition, the qualitative difference in inhabitants' testimonies over the ten-year period shows how their vernacular knowledge system and intimate understandings, both founded in time-tested adaptative practices, work to discern the particularities of change over time. For example, Sakha's centuries-old understanding of the wet years / dry years cycle, in response to which they either hold water in their fields during dry times or release in the wet years. By gauging changes over this ten-year period, it is clear how the wet years have turned to dry years and how the dynamic interplays and feedbacks of both climate change and human interventions have rendered parts of the landscape in permanent wet year conditions. This and the other examples from the 2008 / 2018 comparative exercise illustrate that, when investigating local perceptions, understandings and responses to climate change, the most robust results are had by grounding research in a culture's Indigenous / vernacular knowledge system.

Furthermore, my analysis explored two cultural phenomena. The first was how inhabitants continued to perpetuate a cultural myth, attributing change to a long-disproven driver. By framing this finding within the history of Viliui Sakha's experience with the unjust dam development and continued inequity to this day, it makes sense that inhabitants continue to blame the reservoir and all it symbolizes. The second was how inhabitants expressed starkly contrasting perceptions of change. I used various explanations to understand this, including the human capacity to adapt, intergenerational forgetting and denial in response to overwhelming information. However, based in my longitudinal experience with Viliui Sakha, the explanation that fit best 
was due to Sakha's sacred understanding of the agency of words. This then begs a series of questions: if climate change is not discussed due to these communicative norms, how might it be possible to appropriately discuss such matters; how might it be 'safely' framed; when some people seem ready to talk about it and others are reticent, what might be some ways forward? Again, by framing analyses within the vernacular knowledge with which a population views and interprets their world, such cultural predilections can inform effective inroads to understanding can be made.

Several participants in the focus groups and interviews noted that there were not as many stars in the winter sky as there were before. They said that this was because of the warming winters, so different from the clear, crisp, cold winters of before when there were many, many stars. This discussion triggered a memory of my first winter in Elgeeii in 1993, when I was so in awe at my first sight of the night sky. I was in the backyard of my host's home, a place where the surrounding forest made my window to the sky quite limited. To get a better view, I walked to the nearest open area and stared up. I was in awe to see that there were so many stars, they seemed to overwhelm the dark sky.

Although in many places in the world light pollution cancels out starlight, there has been a minimal increase in night lighting in these regions. The focus group participants who commented about fewer stars went on to say that as the stars go, so go the alaas. This recalled another early memory for me. On my first trip to the Sakha Republic, while staring out the window at the flat landscape dotted with alaas, my seatmate shared a Sakha simile, "There are as many alaas on the land here as there are stars in the sky." I cannot help but wonder, given the rapid change of the permafrost and the resulting cascade of effects through the ecosystem, how important interpretation of both physical phenomena and cultural meanings are to effective research results. This struck me especially when I reached out to a colleague doing long-term work with communities who are expected to have some of the most serious consequences from permafrost degradation in the near future. I asked how the inhabitants were thinking about their future and preparing for this change. He responded, "a small change of subsidy or tax regime, or the cancellation of an aviation route, has far, far more impact on an isolated community than any amount of climate change-which they tend to see as variability, which is what they have always been adapted to face."

I get that. Inhabitants are highly adaptive. And I know from my own research that people are much more focused on day-to-day living 
and on their basic needs to make ends meet. Adaptation is and has been Sakha's central strategy. Their Turkic ancestors adapted a southern horse and cattle subsistence to an extreme continental climate and biome. Sakha adapted to seventeenth-century Russian colonization during which their lands were annexed and they had to pay yasak (fur tribute). In the Soviet period, perhaps the most tumultuous time, Sakha were forced to gradually collectivize their food production, terminating in agro-industrial state farms. Then, the overnight dissolution of those centralized operations forced Sakha to adapt once again. They did so successfully by developing household-level food production systems. Reflecting on this history discursively centers human agency in the face of things that can't be controlled. Sakha prefer to respond and change their behaviors, rather than focusing on the distress of the change itself. However, with climate change, I argue that we are talking about a very different kind of change. Climate change threatens Sakha's displacement from the very ground they walk and thrive upon. Don't we have a role to play in facilitating understanding as our collaborators also contribute greatly to ours?

\section{Acknowledgments}

First and foremost, I acknowledge all of my research collaborators over the yeard, in Yakutsk and the Viliui regions. I hope my work makes a positive contribution. I also acknowledge the three reviewers who provided many useful comments and recommendations to greatly improve the article. For funding, I am grateful to Royal Anthropological Institute / British Museum, Urgent Anthropology Fellowship, 2018-2019 and to the National Science Foundation, Office of Polar Programs, Arctic Social Science Program grants 0710935 and 0532993.

\footnotetext{
Susan A. Crate is an environmental and cognitive anthropologist, who since 2005 has analyzed perceptions, understandings, and responses to climate change among Sakha, arctic Canadian, Peruvian, Welsh, I-Kiribati, Mongolian, and Chesapeake watermen communities. She is the author of numerous peer-reviewed articles, two edited volumes on anthropology and climate change, and two monographs, most recently, Once Upon the Permafrost: Knowing Culture and Climate Change in Siberia (University of Arizona Press, 2021). Service includes the Norwegian Scientific Academy for Polar Research
} 
(2019-present), lead author on the IPCC Special Report on Oceans and Cryosphere (2017-2019) and American Anthropology Association's Task Force on Climate Change (2011-2014). She is a professor at George Mason University. Email: scrate1@gmu.edu

\section{References}

Barnes, J., and M. R. Dove, eds. 2015. Climate cultures: Anthropological perspectives on climate change. New Haven: Yale University Press.

Beck, S., M. Borie, J. Chilvers, A. Esguerra, K. Heubach, M. Hulme, R. Lidskog, E. Lovbrand, E. Marquand, C. Miller, T. Nadim, C. Neshover, J. Settele, E. Turnhout, E. Vasileiadou, C. Gorg. 2014. "Towards a reflexive turn in the governance of global environmental expertise the cases of the IPCC and the IPBES." GAIA-Ecological Perspectives for Science and Society 23 (2): 80-87.

CBC. 2021. "Why this Icelandic writer says 99 percent of climate talk is meaningless “white noise."' https://www.cbc.ca/radio/ideas/why-this-icelandic -writer-says-99-of-climate-talk-is-meaningless-white-noise-1.6060620.

Crate, S. A. 2002 "Co-option in Siberia: The case of diamonds and the Vilyuy Sakha." Polar Geography 26 (4): 289-307.

Crate, S. A. 2003. "The legacy of the Viliui reindeer herding complex." Cultural Survival Quarterly 27 (1): 25-27.

Crate, S. A. 2006a. Cows, kin, and globalization: An ethnography of sustainability. Walnut Creek, CA: Alta Mira Press.

Crate, S. A. 2006b. "Ohuokai: A unique integration of social meaning and sound." Journal of American Folklore 119 (472): 161-183.

Crate, S. A. 2008. "Gone the bull of winter? Grappling with the cultural implications of and anthropology's role (s) in global climate change." Current Anthropology 49 (4): 569-595.

Crate, S. A. 2011a. "Climate and culture: Anthropology in the era of contemporary climate change." Annual Review of Anthropology 40: 175-194.

Crate, S. A. 2011b. "A political ecology of Water in Mind: Attributing perceptions in the era of Global Climate Change." Weather, Climate and Society 3 (3): $148-164$.

Crate, S. A. 2021. Once upon the permafrost: Knowing culture and climate change in Siberia. Tucson: University of Arizona Press.

Crate, S. A. Forthcoming. Sakha and alaas: Place attachment and cultural identity in a time of climate change." Anthropology and Humanism.

Crate, S. A., and A. N. Fedorov. 2013a. "A methodological model for exchanging local and scientific climate change knowledge in northeastern Siberia." Arctic 66 (3): 338-350.

Crate, S. A., and A. N. Fedorov. 2013b. Alamai Tiin: Buluu Ulustarigar Klimat Ularitigar uonna Atin Kihalghar [White spirit: Climate change and other change in the Viliui regons]. Yakutsk: Bichik. 
Crate, S. A., and M. Nuttall, eds. 2009. Anthropology and climate change: From encounters to actions. Walnut Creek, CA: Left Coast Press.

Crate, S. A., and M. Nuttall, eds. 2016. Anthropology and climate change: From actions to transformations. New York: Routledge.

Crate, S. A., M. Ulrich, O. Habeck, A. Desyatkin, R. Desyatkin, A. Fedorov, T. Hiyama, Y. Iijima, S. Ksentofontov, C. Meszaros, and H. Takakura. 2017. "Permafrost livelihoods: A transdisciplinary review and analysis of thermokarst-based systems of indigenous land use." Anthropocene, 18: 89-104.

Cunsolo, A., and N. R. Ellis. 2018. "Ecological grief as a mental health response to climate change-related loss." Nature Climate Change 8 (4): 275-281.

Diaz, S., S. Demissew, C. Joly, W. M. Lonsdale, and A. Larigauderie. 2015. “A “Rosetta Stone for nature's benefits to people." PloS Biology 13 (1): e1002040, doi:10.1371/journal.pbio.1002040.

Dove, M. R., ed. 2013. The Anthropology of climate change: An historical reader. West Sussex: John Wiley \& Sons.

Dyakonov, K. N. 1975. Vliianie krupnykh ravninnykh vodokhranilishch na lesa priberezhnoi zony (The influence of large plain reservoirs on the forests of the coastal zone). Moscow: Gidrometeoizdat.

Ermolaev, V., 1991: Uu Dolgun Kuttaakhtara: Agro-etnograficheskai ocherk [Phases of Yakut (Sakha) land tenure]. Yaktusk: Sakha Book Publishers.

Ferguson, J., 2019. Words like birds: Sakha language discourses and practices in the city. Lincoln: University of Nebraska Press.

Fondahl, G., V. Filippova, A. Savvinova, A. Ivanova, F. Stammler, and G. Hoogensen. 2019. "Niches of agency: Managing state-region relations through law in Russia." Space and Polity 23 (1): 49-66.

Gogolev, A. I. 1993. Iakuti: Problemy etnogeneza i formirovaniia kul'tury [The Yakut: Problems of ethnogenesis and cultural formation]. Yakutsk: Yakutsk State University Press.

Gogolev, A. I. 1994. Mifologicheskii mir Iakutov: Bozhestvo i dukhi-pokroviteli [The mythological world of the Yakut: Gods and spirit-protectors]. Yakutsk: Center of Culture and Art.

Gotovtsev, S. P. 2018. Vodnye katastrofy [Water disasters]. Kiim, March 15, 2018.

Grigorieva, A. M. 2016. Urukky Syllar Sild'aajar Syrdyktara. [The reflection of the past years]. Yakutsk: Ovsvet.

Haarstad, H. 2014. "Climate change, environmental governance and the scale problem." Geography Compass 8 (2): 87-97.

Hiwasaki, L., E. Luna, and S. R. Syamsidik. 2014. Local and indigenous knowledge for community resilience: Hydro-meteorological disaster risk reduction and climate change adaptation in coastal and small island communities. Jakarta: UNESCO.

Hou, L., J. Huang, and J. Wang, 2017. "Early warning information, farmers' perceptions of, and adaptations to drought in China." Climatic Change 141 (2): 197-212.

Huntington, H. P. 2000. “Using traditional ecological knowledge in science: methods and applications." Ecological Applications 10 (5): 1270-1274. 
Ignatieva, V. B. 2014. Izmenenie mirovogo klimata: Lokal'nye proektsii v Respublike Sakha (Iakutiia) [Change in world climate: Local projects in the Sakha Republic (Yakutia)]. In Etnosotsiologicheskie issledovaniia v Respublike Sakha (Iakutia), ed. U. S. Borisova, vol. 1: 78-98. Yakutsk: IGIiPMNS.

IPCC (Intergovernmental Panel on Climate Change). 2019. IPCC special report on the ocean and cryosphere in a changing climate. Eds. H.-O. Pörtner, D. C. Roberts, V. Masson-Delmotte, P. Zhai, M. Tignor, E. Poloczanska, K. Mintenbeck, A. Alegría, M. Nicolai, A. Okem, et al. Geneva: World Meteorological Organization.

IPCC. 2021. "Summary for policymakers." In Climate Change 2021: The Physical Science Basis. Contribution of Working Group I to the Sixth Assessment Report of the Intergovernmental Panel on Climate Change [Ed. Masson-Delmotte, V., P. Zhai, A. Pirani, S. L. Connors, C. Péan, S. Berger, N. Caud, Y. Chen, L. Goldfarb, M. I. Gomis, M. Huang, K. Leitzell, E. Lonnoy, J. B. R. Matthews, T. K. Maycock, T. Waterfield, O. Yelekçi, R. Yu, and B. Zhou]. Cambridge: Cambridge University Press.

Jochelson, W. 1933. "The Yakut." Anthropological papers of the American Museum of Natural History 33 (2). New York: AMNH.

Krauss, J., 2018. "Representing environment and development-tracing links between drivers, representations and power dynamics in cocoa sustainability and beyond." Journal of Political Ecology 25 (1): 426-445.

Kulakovski, A. E. 1979. Nauchnye trudy [Scientific works]. Yakutsk: Yakutsk Book Publishers.

Maak, R. K. [1886] 1994. Viliuiskii okrug [The Viliui okrug]. 2nd ed. Moscow: Yana.

Maldonado, J. K., B. Colombi, and R. Pandya. 2016. Climate change and indigenous peoples in the United States. Cham: Springer International.

Marino, E., 2015. Fierce climate, sacred ground: an ethnography of climate change in Shishmaref, Alaska. Fairbanks: University of Alaska Press.

Mekonnen, Z., H. Kassa, T. Woldeamanuel. and Z. Asfaw. 2017. "Analysis of observed and perceived climate change and variability in Arsi Negele District, Ethiopia." Environment, Development and Sustainability 20 (3): 1-22.

Meyers, S. L. 2019. “China's voracious appetite for timber stokes fury in Russia and beyond." New York Times, April 9. https://www.nytimes.com/ 2019/04/09/world/asia/chinas-voracious-appetite-for-timber-stokes-fury -in-russia-and-beyond.html.

Nikolaev, S. I. 1995. Origins of the Sakha People. Yakutsk: NIPK Sakha polygrafizdat.

Norgaard, K. M. 2011. “Climate denial: Emotion, psychology, culture, and political economy." In Oxford handbook on climate change and society, vol. 18, 399-413.

Orlove, Ben. 2018. Personal communication. June 13.

Rappaport, R. A. 1974. “Obvious aspects of ritual." Cambridge Anthropology: 3-69. 
Sakhalife. 2018. "Voda iz reki Viliui v Mirninskom raione prigodna dlya bytovogo ispol'zovaniia." (The water in the Viliui River and the Mirny region is good for household use) http://sakhalife.ru/voda-iz-reki-vilyuy-v -mirninskom-rayone-prigodna-dlya-byitovogo-ispolzovaniya/.

Seroshevskii, V. L. [1896] 1993. Iakuty. Moscow: ROSSPEN.

Sherpa, Pasang. 2018. Personal communication. November 25.

"Siberia will become a desert! If we don't stop the Chinese" [Sibir' stanet pustynei! Esli my ne ostanovim Kitaitsev]. 2018. YouTube video. https:// www.youtube.com/watch ?v=kfTpDW RHUhM.

Solovyeva, V. 2021. "Climate change in Oymyakon: Perceptions, responses and how local knowledge may inform policy." PhD diss., George Mason University.

Spesivtseva, N. A. 1976. Mikroklimaticheskii rezhim Viliuiskogo vodokhranilishcha (The Microclimatic Regime of the Viliui Reservoir). Yakutsk: Yakutsk Book Publishers

Strauss, S., and B. S. Orlove. 2003. Weather, climate, culture. New York: Routledge.

Svinoboev, A. N., and A. B. Neustroeva. 2017. Izmenenie klimata i usloviia zhizni na Severe $v$ vospriniatii korennogo naseleniia [Climate change and living conditions in the North in the perception of the indigenous population]. Urbanistika 4: 28-39.

Taddei, R. 2013. “On the social performativity of climate forecasts." In Environmental anthropology: Future directions, ed. Helen Kopnina and Eleanor Shoreman Ouimet, 244-263. New York: Routledge.

Tambiah, S. J. 1968. “The magical power of words.” Man 3 (2): 175-208.

Tengö, M., E. S. Brondizio, Elmqvist, P. Malmer, and M. Spierenburg. 2014. "Connecting diverse knowledge systems for enhanced ecosystem governance: The multiple evidence base approach." Ambio 43 (5): 579-591. doi:10.1007/s13280-014-0501-3.

Thaman, R., P. Lyver, R. Mpande, E. Perez, J. Cariño, and K. Takeuchi, eds. 2013. The contribution of indigenous and local knowledge systems to IPBES: Building synergies with science. IPBES Expert Meeting Report, UNESCO/UNU. Paris: UNESCO.

Vinokurova, U. A., and A. Alekseeva 2021. Tuoi-Khaia: Stertaia iz karty, no ne iz pamiati [Tuoi-Khaia: Gone from Maps but not from Memories]. Paper presented at the 10th International Congress of Arctic Social Sciences (ICASS X) Arkhangelsk and Online, June 15-20.

Vinokurova, U. A. et al. 2019. “Liudi na merzlotnykh landshaftakh [People on the permafrost landscape]." Nauka I tekhnika v Iakutii 2(37): 12-15.

Witherspoon, G. 1980. "Language in culture and culture in language." International Journal of American Linguistics 46 (1): 1-13.

Yeh, E. T. 2016. "'How can experience of local residents be "knowledge"?' Challenges in interdisciplinary climate change research." Area 48 (1): 34-40. 